\title{
A Deliberação nos Comentários dos Leitores de Jornais Online Portugueses
}

\author{
Francisco Fontes \\ CEIS20, Universidade de Coimbra - cardosofontes@gmail.com
}

\begin{abstract}
Resumo
Partindo do modelo de democracia deliberativa e da abordagem a alguns dos seus autores, procura analisar-se o discurso que se desenvolve nos espaços de comentário a notícias nos media portugueses.

Se a tecnologia favorece a participação democrática, de que modo a comunicação através dela cumpre as exigências para que a deliberação tenha as condições necessárias para se desenvolver na esfera pública virtual?

Os fóruns criados pelos jornais online são espaços de potencial deliberação. Dão a oportunidade aos participantes de comunicarem e discutirem livremente ideias sobre um determinado assunto.

deliberação online, analisando os comentários a notícias sobre a desfiliação de José Sócrates do Partido Socialista, publicadas na edição online do Jornal de Notícias e no meio eletrónico Observador.

Conclui-se que os espaços de comentários dos jornais tendem a não cumprir os requisitos normativos de esfera pública. Embora apresentem os constrangimentos comuns à conversação pública online, conseguem ainda desenvolver uma interação democrática. Com um olhar diferente dos jornais hospedeiros sobre os espaços de comentários, poderão melhorar o seu potencial para o debate de temas relevantes no espaço público.
\end{abstract}

Este artigo apresenta um estudo de caso de

Palavras-chave: Deliberação, comentários online a notícias, José Sócrates, JN, Observador.

\section{The Deliberation on Reader Commentary by Portuguese Online Newspaper Readers}

\begin{abstract}
Starting with the deliberative democracy model, and the approach by some of its authors, this article aims to analyze the discourse developed in commentary sections of news on Portuguese online media.

If technology favors democratic participation, in what way can the communication

done through it obey the requirements for the deliberation to have the necessary conditions to develop in the virtual public sphere? Forums created by online newspapers are potential deliberation spaces. They give participants the opportunity to freely communicate and discuss ideas on a particular topic.
\end{abstract}


This paper presents a case study on online deliberation, analyzing the commentary on news on José Sócrates' disaffiliation from the Portuguese Socialist Party, published on the online outlets of Jornal de Notícias and Observador.

In conclusion, the commentary sections tend not to comply with the normative require- ments of the public sphere. Although they present the common constraints of online public conversation, they still manage to develop democratic interaction. With the host newspapers taking a closer look on the commentary sections, their potential for debating relevant topics in the public sphere could be improved.

Keywords: Deliberation, online news commentary, José Sócrates, JN, Observador.

\section{INTRODUÇÃO}

A incapacidade de travar o crescente alheamento da participação cívica e política dos cidadãos pela via "tradicional", através da presença física, cara-a-cara e de viva voz, fez depositar na Internet, e na deliberação online, a esperança numa nova ágora.

A ampla acessibilidade da Internet - em banda larga e financeiramente suportável para a generalidade dos cidadãos - e as características da comunicação - fora dos convencionais espaços políticos, com liberdade de expressão, sem constrangimentos nem agenda -, atribuíram aos media sociais essa esperança de estimularem processos de discussão e de formação de opinião pública.

Através desses espaços dialogais fomentados pelos media digitais, almeja-se um revigoramento da intervenção cívica, num ideário de democracia deliberativa.

Embora continue a ser uma esperança adiada nesta dimensão, é inquestionável que a Internet, esse "espaço libertário, anti-autoritário" (Condesso, 2007, p. 31), e enquanto estrutura para a comunicação mediada por computador (CMC), veio revolucionar e ampliar as possibilidades da participação cidadã na esfera pública.

Tendo em atenção tais premissas, procura avaliar-se se os media sociais podem ser uma alternativa, ou mais um dos recursos contemporâneos, para a participação dos cidadãos em fóruns discursivos que testem na prática o modelo de democracia deliberativa. 
Os espaços de comentários dos jornais, ao mesmo tempo que procuram criar comunidade, ampliando audiências e estimulando a geração de receitas publicitárias, despertam para uma intervenção cívica, uma cidadania ativa.

Esses fóruns são a oportunidade de os cidadãos expressarem as suas posições sobre assuntos públicos, recorrendo ao potencial da comunicação interativa e desterritorializada da Internet.

Neste contexto, o presente artigo procura dar um contributo para o estudo da participação em fóruns deliberativos no contexto da sociedade portuguesa, ao analisar de que forma se expressam as tentativas de exercício da deliberação em espaços de comentário de dois jornais online.

Propõe-se a análise dos comentários a notícias publicadas a 4 de maio de 2018, no JN online e no meio digital Observador, sobre a desfiliação de José Sócrates do PS, do qual fora Secretário-geral, e durante 6 anos Primeiro-ministro de Portugal, em resultado de vitórias eleitorais do Partido Socialista. Este ato surge após comentários negativos de altos dirigentes do partido em torno do mega-processo judicial por corrupção, designado de Operação Marquês, no qual Sócrates é o principal arguido.

\section{OS FÓRUNS ONLINE E O MODELO DELIBERATIVO}

Com a criação dos fóruns online, os jornais dispõem-se a ouvir os seus leitores, criando um canal de comunicação bidirecional, ao mesmo tempo que fomentam nessas audiências a interação entre si. É a aceitação de que o público "tem de o ser" como parte do processo da produção noticiosa, nesta era dos novos media (Gillmor, 2005, p. 118).

A Internet que, nas palavras de Gillmor, "é o primeiro meio de que o público é o proprietário, o primeiro meio que deu voz ao público" (2005, p. 119), possibilita a comunicação e discussão livre de ideias, numa aproximação à noção de esfera pública virtual e de democracia deliberativa.

"[O] ideal da democracia deliberativa procura justamente adaptar as instituições políticas às sociedades complexas, descentralizadas, pluralistas, multiculturais, que as formas tradicionais, dominantes, de representação política tendem a trair", refere Gil Baptista Ferreira (2012, p. 5), em alusão às teses de Jürgen Habermas, a principal referência teórica deste modelo. 
Nas palavras de Habermas, citado por Rheingold:

Por "esfera pública" entendemos antes de mais um domínio da nossa vida social na qual pode formar-se a opinião pública. $\mathrm{O}$ acesso à esfera pública está, em princípio, aberto a todos os cidadãos. Constitui-se uma porção de esfera pública de cada vez que as pessoas individuais se reúnem para falar, formando o público (...). Os cidadãos agem como público quando abordam questões de interesse geral sem estarem sujeitos a coação, estando assim garantida a sua liberdade de reunião, expressão e publicidade de ideias (1996, p. 341).

Habermas chama a atenção para a "íntima relação entre esta teia de comunicações livres, informais e pessoais e os fundamentos da sociedade democrática" (Rheingold, 1996, p. 342).

Nesta linha de pensamento, os indivíduos "só são capazes de se autogovernarem se comunicarem abertamente, livremente e em grupos - ou seja, publicamente" (Rheingold, 1996, p. 342). Eles "são chamados a considerar alternativas e diferentes pontos de vista, que avaliam criticamente, formando a partir deles juízos de valor", tomando uma decisão que só se torna legítima se for o resultado de um processo de deliberação generalizado (Ferreira, 2010, p. 100).

Diz-nos Habermas:

Uma possibilidade de compreender o papel epistémico de tais deliberações práticas reside na descrição exata de como, do ponto de vista moral, os interesses pessoais que entram na deliberação como motivos racionais mudam o seu papel e significado no curso da argumentação. Nos discursos práticos "contam", isto é, para o resultado, apenas aqueles interesses que se apresentam como valores intersubjetivamente reconhecidos e que são candidatos a serem admitidos no conteúdo semântico das normas válidas. (Habermas, 1998, p. 155).

Ferreira (2010, p. 101) afirma que esta ideia de democracia "implica a procura de novas formas de expandir e de institucionalizar os processos deliberativos, e novos mecanismos para alimentar esses mesmos processos e implementar os seus resultados". 
[Q]uanto mais os indivíduos forem capazes de participar na deliberação de questões que lhes dizem respeito, e quanto mais os resultados de tais deliberações forem alimentados com procedimentos que permitam a realização da decisão, mais elevados serão os padrões democráticos na organização política e social das suas vidas.(Ferreira, 2010, p. 101)

A partir de tais considerações, pode reforçar-se que na deliberação, enquanto processo aberto, quanto mais informação estiver disponível, e quanto mais os indivíduos considerarem os argumentos e as reivindicações dos outros, mais poderão modificar os seus pontos de vista originais.

A democracia deliberativa distingue-se de outras teorias ao "enfatizar a necessidade do debate público e da troca de razões sobre o que é justo" (Ferreira, 2012, p. 6), mas só estando informados é que os cidadãos podem ter uma participação racional no debate das questões políticas.

Zizi Papacharissi (2002, p. 22) realça que o acesso fácil, rápido e de baixo custo à informação não resulta, necessariamente, em cidadãos mais informados nem mais propensos a participar na discussão política, embora admita que uma maior participação deles no debate "ajuda, mas não assegura uma democracia mais saudável".

É papel dos media manter os cidadãos informados, dotando-os das 'ferramentas' para serem os atores políticos de que a democracia necessita (Ferreira, 2012, p. 12). Contudo, Michael Schudson (2010, p. 40) aponta um intrínseco constrangimento nessa missão, ao afirmar que geralmente o jornalismo não consegue apresentar às suas audiências uma imagem das reais complexidades da democracia moderna.

É frequente a retórica dos jornalistas e académicos ao falarem de jornalismo pressupor que os meios de comunicação social informam as pessoas e estas depois 'decidem'. (...) Os eleitores raramente decidem diretamente sobre políticas públicas, decidindo antes quais os indivíduos ou partidos que devem assumir a responsabilidade pela execução das políticas públicas.(Schudson, 2010, p. 40)

Como contestação ao modelo que sobressai nesta ideia de Schudson de representação, surgem os defensores da democracia deliberativa, "ao negar, entre outros aspectos, o carácter privado da formação das preferências agregadoras, e ao enfatizar a necessidade do debate público e da troca de razões sobre o que é justo" (Ferreira, 2012, p. 6). 
Se num regime representativo o comum seja os cidadãos votarem nos seus representantes, para John Rawls (2014, p. 168) os cidadãos idealmente "devem conceber-se como se fossem legisladores", que cumprem "o seu dever de civilidade e apoiam a ideia de razão pública”.

Quando os cidadãos deliberam, trocam pontos de vista sobre questões políticas públicas e debatem as razões que sustentam essas opiniões. Partem do princípio de que as suas opiniões políticas podem ser revistas através da discussão com outros cidadãos; e, por conseguinte, essas opiniões não são simplesmente o produto fixo dos seus interesses privados ou não-políticos prévios. É nesse ponto que a razão pública é crucial, pois caracteriza a argumentação de tais cidadãos acerca de fundamentos constitucionais e questões de justiça básica. (Rawls, 2014, p.172)

Para Rawls (2014, p.172), há três elementos essenciais na democracia deliberativa: a ideia da razão pública, as instituições democráticas constitucionais e o conhecimento e desejo dos cidadãos de seguirem a razão pública e concretizarem o seu ideal na conduta política.

No entanto, este modelo necessita que haja uma educação generalizada dos cidadãos sobre o regime de governação democrática, e que o público tenha informação sobre os assuntos que o afetam, que são prementes, para que possa tomar as decisões políticas e sociais que se impõem (Rawls, 2014, p. 173).

Nesta perspetiva, a deliberação destaca, do ideário democrático de onde emerge, as ideias de igualdade política, de debate racional e equitativo, de razão pública, de autoridade e legitimidade da decisão.

Ferreira sintetiza o modelo de democracia deliberativa deste modo:

[B] aseia a tomada de decisões políticas na troca de razões e argumentos, num processo em que todos os cidadãos participam para além dos seus interesses pessoais, com o objectivo de alcançar o bem comum - distinguindo-se dos mecanismos de pura agregação das vontades individuais que marcava o modelo representativo liberal. As minorias podem ser afastadas do espaço público e empurradas para as margens pelos mecanismos de agregação, assim, a deliberação apresenta-se como forma de atrair essas margens. (2012, p. 9) 
Para este autor, as tecnologias da comunicação podem potenciar a ampliação das "arenas da vida pública" (Ferreira, 2012, p. 7) e serem inclusivas ao trazer para o debate cidadãos que normalmente não têm participação nos fóruns presenciais, ou deles são marginalizados.

Mike S. Schäfer (2015, p. 322) reconhece que a esfera pública digital tende a tornar visíveis os diversos atores e suas posições, que por vezes são influenciadoras e vinculantes, mas, por outro lado, apresenta uma variedade de estilos comunicativos que "raramente se conformam às ideias de racionalidade e civilidade, defendidas pela teoria participativa e deliberativa".

No mesmo sentido, Manuel Castells (2003, p. 428) vê na comunicação eletrónica uma das alternativas à construção da democracia, ao estimular formas de participação política e comunicação horizontal entre os cidadãos.

Com efeito, o acesso on-line a informações e a comunicação mediada por computador facilitam a difusão e a localização de informações, proporcionando a interação e os debates em fóruns eletrónicos independentes (...). Caso essa variante de política democrática se instaure como um importante instrumento de debate, representação e decisão, certamente institucionalizará uma forma de "democracia ateniense", tanto a nível nacional como internacional. (Castells, 2003, p. 429)

Ferreira (2012) refere que para os defensores da "democracia eletrónica" a tecnologia da Internet "pode ser explorada para tornar o processo político mais inclusivo e deliberativo" (p. 39), pois esses dispositivos "reúnem as condições para responder aos requisitos básicos da teoria normativa habermasiana sobre a esfera pública democrática" (p. 42).

Tais dispositivos são

meios universais, anti-hierárquicos, que oferecem comunicação não coerciva, liberdade de expressão, agenda sem restrições e comunicação fora das tradicionais instituições políticas. Assim entendido, o potencial destes dispositivos de comunicação permite a formação de opinião pública mediante processos de discussão numa escala largamente superior à dos media convencionais. (Ferreira, 2010, p. 103) 
James Fishkin, citado por Ferreira (2010, p. 111), enumera três condições para que se torne possível a deliberação face-a-face: "que as mensagens políticas possam ser trocadas em toda a extensão; que haja oportunidade de reflexão sobre novas mensagens, e para o seu debate reflexivo; que as mensagens sejam testadas intersubjetivamente, em confronto com argumentos rivais".

Diretor do Centro de Democracia Deliberativa na Universidade de Stanford, Fishkin tem feito experiências do modelo em várias partes do mundo. Da sua experiência afirma que, apesar de haver estudiosos a demonstrar que o público é estúpido, os resultados que ele próprio apurou evidenciam que é potencialmente muito inteligente. Só é preciso haver condições sociais, uma estrutura a que prestem atenção, boa informação e argumentos concorrentes para serem "consistentemente brilhantes". Foi assim que aconteceu na antiga Atenas (Fishkin, 2013).

O entusiamo pela Internet como uma outra ágora é refreado por vários autores, entre eles Lincoln Dahlberg, que encontram no modo como a plataforma está estruturada constrangimentos ao diálogo aberto, livre, crítico, reflexivo e racional dos cidadãos; ou seja, a uma concretização normativa de esfera pública inspirada no modelo teórico de Habermas.

Dahlberg (2004, p. 29) entende que, para se ter "confiança na avaliação crítica da prática comunicativa online, precisamos de uma conceção normativa convincente da esfera pública”, e é o que ele próprio procura desenvolver em vários estudos a partir do modelo teórico do sociólogo alemão, a que incorpora contributos de outros autores. Considera o modelo de Habermas "um forte ponto de partida para uma análise crítica" (2004, p. 39).

Comparando as condições normativas da esfera pública com o funcionamento do ciberespaço, Dahlberg (2001) argumenta que a censura e vigilância do Estado e a comercialização e aumento do controlo das infraestruturas e dos conteúdos da Internet ameaçam a interação online e a livre expressão pública.

Reconhece, no entanto, que a interação online continua a ocorrer sobre múltiplos temas de forma crítica, que ainda se encontram espaços para a livre expressão, que a reflexividade argumentativa também se verifica, embora inibida pela velocidade das trocas na rede, e "muito aquém do que é exigido pela noção da esfera pública". Contudo, admite que são escassas as situações em que se desenvolve uma interação empenhada sobre tópicos, e que o mais comum é ocorrer uma interação "fragmentada em grupos de valores e interesses semelhantes". 
Partindo de tal constatação, Dahlberg sugere que

[a] reflexividade tem de ser aumentada no discurso online para que a conceção da esfera pública seja mais completa. Uma tarefa importante para melhorar a reflexividade é fazer com que os participantes ouçam respeitosamente e, assim, chegar a um entendimento da posição do seu interlocutor (2001).

Outro dos constrangimentos apontados por Dahlberg (2001) à deliberação online relaciona-se com a falta de sinceridade - por via da adoção de falsas identidades, pela ação de trolls em divertimento ou a prejudicar intencionalmente a interação no grupo - e pela partilha de informação falsa, designadamente, por razões políticas, para desinformar, confundir, envergonhar ou autopromover.

A igualdade discursiva e a inclusão, propaladas pelos mais entusiastas da Internet, sofrem, igualmente, de constrangimentos. Grandes franjas da população adulta no mundo continuam sem acesso à Internet e, quando dele dispõem, muitas das pessoas "simplesmente não têm tempo, capital cultural ou apoio comunitário para se envolverem em deliberações políticas", e ao descurar tais exclusões pode estar-se a "apoiar uma esfera pública de elite" (Dahlberg, 2001).

Embora com algumas diferenças, derivadas dos contextos, o que se constata é que as desigualdades discursivas offline reproduzem-se online, desdizendo uma alegada 'cegueira' do ciberespaço à identidade. Mesmo em situações de anonimato, há elementos identitários que são percecionados por aquilo que cada um não consegue deixar de revelar.

Segundo Dahlberg (2001), os fatores que desenvolvem a reputação no ciberespaço têm a ver com o tempo que é gasto online, a capacidade argumentativa e de conhecimento dos assuntos, a frequência e a fiabilidade das publicações. A partir daí desenvolvem-se relações de poder e hierarquias, com alguns a "fazer ouvir as suas vozes mais do que outros, o que leva ao domínio do discurso por certos indivíduos ou grupos e, assim, às desigualdades discursivas".

Em síntese, Dahlberg (1998, p. 78) realça que certas posições entusiastas do potencial da Internet para estimular a esfera pública tendem a desenquadrar o meio tecnológico das redes informáticas do contexto social, e acrescenta que o seu potencial para melhorar a democracia está a ser adulterado pelo controlo comercial, censura e privatização dos espaços de interação. 
Iris Marion Young (2014), num trabalho em que confronta o ativismo político democrático com a democracia deliberativa, lança interrogações sobre o cumprimento do ideal de debate aberto de ideias e posições em prol de soluções justas, em sociedades com desigualdades estruturais.

Zizi Papacharissi (2002, p. 21), por seu turno, é de opinião que "o atual estado das relações sociais da vida real dificulta tanto a criação de uma esfera pública no mundo virtual como no real", e que aquilo que o ciberespaço oferece às pessoas é um alargamento dos canais de comunicação, mas "sem afetar radicalmente a natureza da comunicação".

Young (2014) questiona se os procedimentos de deliberação não são excludentes, se não tendem a beneficiar os participantes mais poderosos, pondo em causa a força do argumento que confronta os interesses de uns e de outros, no sentido de uma solução justa comum.

Mesmo com preocupações inclusivas, de ampla abertura a todas as partes interessadas, interroga se o processo deliberativo não ativa, ainda, "vieses estruturais pelos quais os atores mais poderosos e socialmente favorecidos (...) conseguem dominá-lo com seus interesses e perspetivas" (Young, 2014, p. 199).

O próprio discurso comum da sociedade, que é levado para a discussão, para expor ideias e factos, que explica as dinâmicas sociais, as normas, os valores culturais, não estará também ele contaminado pelas próprias desigualdades estruturais (Young, 2014, p. 205)? Constata-se que o questionamento das narrativas dominantes, padronizadas, das representações discursivas, continua no centro do debate quotidiano das sociedades, sobre temas tão distintos como género, pobreza, religião, cultura, crença ou educação.

[A]s pessoas podem chegar a um acordo que é, no entanto, pelo menos em parte, condicionado por relações de poder injustas e que, por essa razão, não deve ser considerado um consenso realmente livre. (...) Quando esse discurso hegemónico opera, as partes envolvidas na deliberação podem concordar sobre as premissas, aceitar uma teoria sobre sua situação e apresentar as razões para propostas que os outros aceitam, mas, mesmo assim, as premissas e as condições dessa visão mascaram a reprodução do poder e da injustiça (Young, 2014, p. 206). 
Segundo Young (2014, p. 207), a teoria e a prática da democracia deliberativa não dispõem de ferramentas para rebater a possibilidade de as deliberações poderem ser distorcidas desse modo, por carecer "da ideologia, bem como de uma visão da genealogia dos discursos e da maneira de ajudar a constituir a forma como as pessoas se veem a si mesmas e ao seu mundo social".

Esse nível da influência da desigualdade estrutural sobre a discussão publica é o mais insidioso por ser o menos evidente a todos os participantes. Está relacionado ao marco conceitual e imagético da discussão, que muitas vezes contém falsificações, preconceitos, incompreensões e até mesmo contradições que passam sem ser percebidos nem criticados, em grande parte porque coincidem com os interesses hegemónicos ou refletem as realidades sociais existentes como se fossem inalteráveis (Young, 2014, p. 207).

Pelas caraterísticas do ciberespaço, o processo deliberativo confronta-se, ainda, com um problema epistémico, que é o de recolher informação relevante e confiável num ambiente de rápida mudança, tornando o desafio ainda mais ousado quando se pretende desenvolver conhecimento sobre um assunto (Dahlgren, 2018, p. 20).

Para o mesmo autor (2018, p. 22), um comum utilizador encara a Internet como um manancial quase inesgotável de informação, em que a "certeza cognitiva é desalojada” pelo excesso, gerando, assim, a dúvida, que a um certo nível poderá até estimular o diálogo democrático, o confronto de ideias e a própria deliberação.

Reproduzindo o pensamento de Mark Andrejevic, Dahlgren (2018, p. 22) destaca que múltiplas versões concorrrentes de factos e de conhecimentos produzem visões inconciliáveis da realidade, "cimentando e isolando bolhas discursivas incompatíveis, e desgastando os fundamentos da discussão política”.

Porém - acrescenta Dahlgren (2018, p. 22) -, a "tomada de decisão requer reflexão, o que, por sua vez, também exige tempo". Em consequência, a "atenção torna-se fragmentada", relegando as pessoas para "micro-zonas cada vez menores de envolvimento atento".

Este contexto - acrescenta - gerou "um dilema historicamente novo para a democracia, onde não só a desconfiança se aprofundou, como também os motivos para estabelecer e legitimar a 'verdade' se desestabilizaram” (Dahlgren, 2018, p. 23).

Perante a constatação de que a comunicação democrática online não se esgota na deliberação, e que o modelo deliberativo não dispunha das ferramentas teóricas para 
uma análise capaz da diversidade dessa discursão, alguns autores avançaram com propostas de abordagens mais transversais.

Deen G. Freelon (2010, p. 1176) avançou com uma proposta de abordagem à comunicação democrática online a partir de três modelos: 'liberal individualista,' 'comunitário' e 'deliberativo', sendo este último uma aproximação aos tópicos que neste artigo já foram enunciados por referência a Habermas e Dahlberg.

O 'liberal individualista' é descrito como uma comunicação tendencialmente em monólogo, que procura apresentar a pessoa e suas ideias, com a interação gerada praticamente centrada na resposta a perguntas colocadas. O 'comunitário' caracteriza-se por uma identidade grupal, que por sua vez desenvolve uma fragmentação ideológica e pode tender para a mobilização política, bem como para a promoção de uma conversação intra-ideológica, comum ao modelo 'deliberativo', embora se possa desenvolver apenas entre membros do grupo e com menor transversalidade do que este.

Lincoln Dahlberg (2011, p. 856), num artigo posterior ao de Freelon, avança também com quatro posições de análise da democracia digital - 'liberal-individualista', 'deliberativa', 'contra-pública' e 'marxista autonomista' -, partindo de uma categoria geral englobadora de um conjunto de fenómenos tipificadores da complexidade da experiência humana, "retórica, práticas, identidades e instituições".

A liberal-individualista utiliza os meios digitais "para a transmissão eficaz de informações e pontos de vista entre indivíduos e processos representativos de tomada de decisão". A democracia é a "expressão e a agregação das vontades dos indivíduos, e a concorrência entre representantes para o apoio desses indivíduos". A visão geral é de "um "mercado de ideias" (Dahlberg, 2011, p. 858).

A 'deliberativa' parte do modelo habermasiano. A 'contra-público' reporta-se à utilização da rede na formação de grupos políticos para o ativismo e contestação. A 'marxista autonomista' aponta para "participação auto-organizada e inclusiva em atividades produtivas comuns", com um propósito de democracia ideal (Dahlberg, 2011, p. 859).

"Compreender e documentar as relações de uso político da internet pode ajudar-nos a determinar se este meio relativamente novo conseguirá transcender do espaço público para uma esfera virtual e pública"; o seu valor "reside no facto de abranger a esperança, a especulação e os sonhos do que poderia ser", afirma Papacharissi (2002, p. 23).

Partindo do enquadramento teórico supra apresentado, e no sentido de avaliar o potencial da comunicação online para responder aos requisitos básicos do modelo 
deliberativo, realizou-se um estudo centrado nos comentários a notícias publicadas em dois media eletrónicos de Portugal.

\section{METODOLOGIA E RESULTADOS}

Este artigo, tal como enunciado de modo sumário anteriormente, debruça-se sobre a atividade interativa nos espaços de comentário às peças noticiosas nos sites dos dois jornais. A sua localização, a seguir às notícias, permite aos utilizadores a leitura do texto noticioso, apresentar os seus pontos de vista sobre o tema, mas também interpretar e discutir os pontos de vista de outros participantes, procurar o consenso, e deliberar.

Os espaços de comentários a notícias são considerados dos fóruns de discussão mais promissores à participação e interação online, em virtude de a sua associação a órgãos de comunicação social proporcionar mais visibilidade à atividade dos utilizadores (Gonçalves, 2018, p. 604).

O corpus deste trabalho é constituído por 264 comentários a peças jornalísticas publicadas a 4 de maio de 2018 na edição digital do Jornal de Notícias (www.jn.pt), - "Críticas levam Sócrates a abandonar o PS" (Silva H. T., 2018) - e no jornal online Observador (www.observador.pt) - “O ‘embaraço’ de Sócrates com o PS. O texto do 'animal feroz' nas entrelinhas” (Carrapatoso, 2018).

\section{Figura 1}

Publicações do JN e Observador
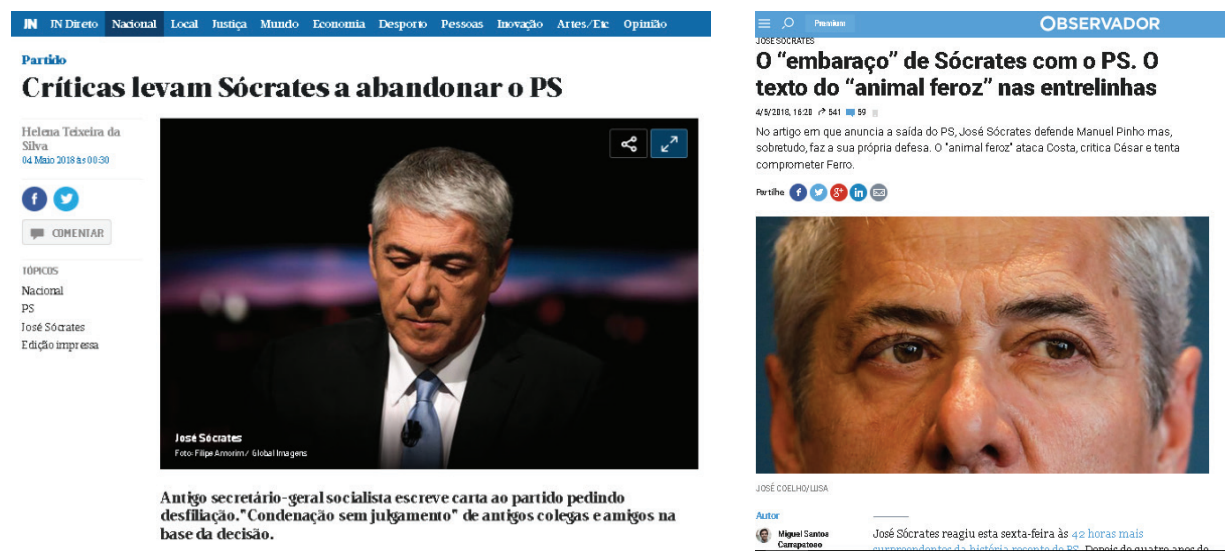
No JN foram publicados 205 comentários e 59, no Observador, de acordo com uma extração efetuada pelas $00 \mathrm{~h} 00$ de 31 de maio de 2018. Na primeira semana da publicação, mais particularmente até à compilação efetuada para este trabalho, pelas 23 h30 do dia 9 de maio de 2018, o Observador já tinha recebido os 59 comentários e o $J N, 202$. Na semana seguinte à da publicação, o JN registou mais três comentários de uma leitora, a "corrigir"/“moderar" comentários de outros participantes.

O JN foi o primeiro jornal a noticiar o envio da carta de desfiliação do PS, numa peça jornalística publicada às $00 \mathrm{~h} 30$ de 4 de maio. Também foi este jornal a publicar na íntegra a missiva enviada por José Sócrates à direção do partido, em formato de artigo de opinião, pelas $09 \mathrm{~h} 27$ desse mesmo dia.

A escolha do Observador para este estudo - sobre um tema político controvertido na sociedade portuguesa - teve em atenção a circunstância de ser um dos órgãos de comunicação social que se apresentava como dos mais críticos à ação pessoal e política de Sócrates. O enquadramento do assunto, no título e lead da notícia, com recurso à expressão "animal feroz", indicia tal postura do jornal, e evidencia a não neutralidade jornalística, e até uma explícita hostilidade para com este personagem da história política de Portugal.

Neste trabalho foi utilizado o método quantitativo para medir o comportamento dialógico dos participantes no fórum, a partir de critérios de análise de conteúdo pré-estabelecidos, que tiveram como guia de orientação as teses sobre a esfera pública e vida cívica de Jürgen Habermas, em particular as desenvolvidas na Teoria da Ação Comunicativa.

Para participar no espaço de comentários, ambos os jornais exigem registo prévio aos leitores. O JN utiliza um plug-in do Facebook, que conecta com o perfil do utilizador nessa rede social. O Observador recorre a um registo mais convencional, com um nome de utilizador real ou inventado, e ativado a partir de uma conta de e-mail.

Em nenhum dos casos é assegurada a identidade real do participante no fórum de comentários e, em muitos deles, a aparência de se tratar de identidades falsas é notória. No caso do Observador, pela criatividade na designação das identidades, e no JN, pelos perfis de um canídeo, de outros vazios de comunidade, e de outros ainda com nomes pouco verosímeis.

Para atribuir identidade aos comentadores, feminina ou masculina, partiu-se de um pressuposto de verosimilhança ao real, e da presença de foto no perfil do Facebook, no caso do JN. Por esta razão, o número e a percentagem de não identificados é muito superior no Observador. 
A moderação por parte dos órgãos de comunicação social não é percetível, embora haja um comentário de um leitor do $J N$ a queixar-se de apagamento de uma mensagem sua. Também não está presente um mecanismo de moderação por denúncia de comentários abusivos pelos participantes, como é adotado por algumas publicações online.

No presente estudo, procurou-se avaliar as potencialidades deliberativas segundo os seguintes critérios: 'Diálogo', 'Foco', 'Contributo para o Debate, 'Civilidade,' 'Posicionamento', 'Entendimento do Assunto' e 'Reflexividade’.

Mediu-se também a identificação por géneros, mas dada a baixa fiabilidade para se estabelecer a identidade verdadeira ou falsa dos participantes não se procurou avaliar eventuais divergências entre identidades reais ou ocultas. Estes resultados são referidos aqui apenas em termos quantitativos, sem avaliações comparatísticas sobre as ações dialógicas.

No 'Diálogo' avalia-se o tipo de atividade, se foi para comentar a notícia, ou se foi para interagir, para comentar mensagem de outro interveniente. No 'Foco', indaga-se se o comentário está centrado no tema da peça noticiosa (o tópico que é notícia, a desfiliação de Sócrates do PS), se em outras personagens referidas, ou em assuntos novos. Em 'Contributo para o Debate' avalia-se o envolvimento cognitivo do assunto. No 'Posicionamento' procura perceber-se se o comentário se expressa em sentido positivo ou negativo, se apoia a posição de Sócrates, ou se o critica, se manifesta concordância, ou não, em relação a outros comentários, ou se diverge do tema em debate. Em 'Entendimento do Assunto' pretendeu avaliar-se o contributo para o debate através de uma atitude crítico-racional. Em 'Reflexividade' mede-se o envolvimento na procura de consensos em torno do tema em debate.

Pela natureza algo fluída do tópico 'Civilidade', e para delimitar o seu âmbito, recorreu-se a alguma literatura (Papacharissi, 2004), (Gonçalves, 2018), (Ziegele, Springer, Jost, \& Wright, 2017), (Coe, Kenski, \& Rains, 2014) e ao entendimento do “cidadão médio”. Em 'Civilidade' incluíram-se a subcategorias 'Flaming,'Trolling' e 'Nenhuma Daquelas', sendo as duas primeiras associadas aos comportamentos que põem em causa valores coletivos e de funcionamento da própria democracia: atitudes difamatórias, insultuosas, discursos de ódio, a violação de outros valores democráticos por desrespeito e falta se sinceridade. Na terceira subcategoria foram enquadradas as noções de cortesia e indelicadeza, comportamentos de rudeza e de alguma agressividade, admitindo-se que diálogo acalorado é reflexo de liberdade de expressão, e que esta abordagem mais elástica aos comportamentos online traduz-se em 
benefício para o debate democrático (Papacharissi, 2004, p. 261).

A linha demarcadora entre a terceira subcategoria e as duas primeiras foi estabelecida entre o diálogo ainda racional e o que já transgride valores sociais, ameaça a democracia e viola as liberdades das pessoas.

A título de exemplo, expressões como "psicopata doido", "palhacito és tão ridículo", "esquizofrenia paranoide" foram enquadradas como de incivilidade. Entre as expressões ainda aceitáveis a uma comunicação cívica incluíram-se "todos a comer na mesma gamela", "arranjem uma chucha" ou "este gajo".

Passando para a análise dos resultados, com as reservas referidas acima sobre a identidade dos participantes, verificamos que os do sexo masculino representam mais de três quartos dos comentadores das notícias. No caso do Observador, mesmo que metade dos não identificados sejam mulheres, a sua percentagem ficará aquém das $23 \%$ percecionadas no $J N$. Independentemente dos números reais, os indicadores aqui expressos levam a concluir que o perfil do participante nesse fórum é masculino.

\section{Quadro 1}

Participação por género

\begin{tabular}{cccc}
\hline Categoria & Subcategoria & $\begin{array}{c}\text { Ocorrências - JN } \\
\text { edição digital }\end{array}$ & $\begin{array}{c}\text { Ocorrências - Ob- } \\
\text { servador }\end{array}$ \\
\hline $\begin{array}{c}\text { Identificação } \\
\text { dos autores dos } \\
\text { comentários/ } \\
\text { participantes }\end{array}$ & Masculino & $155(75,61 \%)$ & $40(67,8 \%)$ \\
& Feminino & $48(23,41 \%)$ & $6(10,17 \%)$ \\
\hline
\end{tabular}

Tendo presente as condições de registo dos comentadores, e as identidades apresentadas, há indícios de em elevado número serem falsas. Este comportamento põe em causa o requisito normativo da sinceridade, essencial aos processos deliberativos. Vários estudos evidenciam que o anonimato, em vez de libertar os participantes para uma discussão sem receios, mais livre e igualitária, "parece resultar num aumento do número de ataques verbais de maior violência e em práticas de insulto e humilhação, entre outras formas de incivilidade" (Ferreira, 2010, p. 110), dimensões que se aprofundarão quando se abordarem o flaming e o trolling. 


\section{Quadro 2}

Tipo de comunicação

\begin{tabular}{cccc}
\hline Categoria & Subcategoria & $\begin{array}{c}\text { Ocorrências - JN } \\
\text { edição digital }\end{array}$ & $\begin{array}{c}\text { Ocorrências - Ob- } \\
\text { servador }\end{array}$ \\
\hline \multirow{2}{*}{ Diálogo } & $\begin{array}{c}\text { Dirigido à notícia / } \\
\text { artigo (monólogo) }\end{array}$ & $106(51,71 \%)$ & $34(57,63 \%)$ \\
& $\begin{array}{c}\text { Dirigido a outro co- } \\
\text { mentário (diálogo) }\end{array}$ & $94(45,85 \%)$ & $22(37,29 \%)$ \\
& A nenhum daqueles & $5(2,44 \%)$ & $3(5,08 \%)$ \\
\hline
\end{tabular}

Qual o impulso para comentar? O leitor tanto o poderá fazer por estímulo do artigo, ou de comentários de outros leitores, ou por ambas as razões. Daí resulta uma comunicação pública unidirecional ou interativa (Springer, Engelmann, \& Pfaffinger, 2015, p. 799).

Na categoria 'Diálogo', a natureza monológica sobrepõe-se à dialógica, numa percentagem de $20 \%$ no Observador, em que perto de $58 \%$ dos participantes preferiram emitir a sua opinião, em vez de procurarem discutir pontos de vista. Talvez o enquadramento da notícia do Observador, com o uso da expressão "animal feroz" no título, tenha contribuído para este resultado. Nos comentários à notícia do $J N$, que se aproxima mais das práticas jornalísticas de distanciamento em relação ao assunto noticiado, há uma separação de apenas 6 pontos percentuais, embora a conversação monológica continue a sobrepor-se à dialógica.

Estudos realizados em vários países revelam que entre 20\% e 50\% dos comentários a notícias são interativos; ou seja, têm referência a comentários de outros utilizadores (Ziegele et al., 2018, p. 1420). Os resultados aqui apurados estão acima desses valores médios (Observador) e próximo dos limites máximos (JN). 


\section{Quadro 3}

Foco dos comentários

\begin{tabular}{lccc}
\hline Categoria & Subcategoria & $\begin{array}{c}\text { Ocorrências }-J N \\
\text { edição digital }\end{array}$ & $\begin{array}{c}\text { Ocorrências - } \\
\text { Observador }\end{array}$ \\
\hline Foco dos comentários & $\begin{array}{c}\text { O tema da notícia ou } \\
\text { artigo }\end{array}$ & $36(17,56 \%)$ & $3(5,08 \%)$ \\
& $\begin{array}{c}\text { Intervenientes na notí- } \\
\text { cia ou artigo }\end{array}$ & $143(69,76 \%)$ & $44(74,58 \%)$ \\
& A nenhum daqueles & $26(12,68 \%)$ & $12(20,34 \%)$ \\
\hline
\end{tabular}

O foco dos comentários é, em percentagens muito elevadas, nos intervenientes das notícias. No caso em análise, o protagonista, José Sócrates, foi um controverso líder do maior partido português na atualidade, é uma personagem política e social com uma postura de confronto, e está indiciado num processo crime por corrupção. As personagens secundárias das notícias são altos dirigentes políticos, e outros cidadãos de elevado estatuto no setor financeiro português. O enquadramento 'hostil' da notícia em relação a Sócrates poderá explicar os resultados apurados nos comentários do Observador, com $75 \%$ a dirigirem-se a intervenientes da notícia e apenas 5\% ao tema da notícia, o ato de desfiliação do partido. Um outro resultado que pode explicar-se pelo enunciado acima são os $20 \%$ que fazem comentários com foco divergente, uma boa parte dos quais para insultar outros leitores pelo teor das opiniões expressas. 


\section{Quadro 4}

Contributo para o debate

\begin{tabular}{|c|c|c|c|}
\hline Categoria & Subcategoria & $\begin{array}{l}\text { Ocorrências - JN } \\
\text { edição digital }\end{array}$ & $\begin{array}{l}\text { Ocorrências - } \\
\text { Observador }\end{array}$ \\
\hline \multirow{7}{*}{$\begin{array}{l}\text { Contributo } \\
\text { para o debate }\end{array}$} & Acrescenta informação & $9(4,39 \%)$ & $4(6,78 \%)$ \\
\hline & $\begin{array}{c}\text { Corrige informação da notícia ou } \\
\text { artigo }\end{array}$ & $0(0 \%)$ & $0(0 \%)$ \\
\hline & Corrige cometário de outro utilizador & $26(12,68 \%)$ & $3(5,08 \%)$ \\
\hline & Dá opinião & $119(58,05 \%)$ & $38(64,4 \%)$ \\
\hline & $\begin{array}{c}\text { Fundamentação/racionalidade } \\
\text { na ideia apresentada }\end{array}$ & $38(18,54 \%)$ & $7(11,87 \%)$ \\
\hline & Acrescenta experiência pessoal & $2(0,98 \%)$ & $0(0 \%)$ \\
\hline & Nenhum & $11(5,37 \%)$ & $7(11,87 \%)$ \\
\hline
\end{tabular}

Ao analisar-se o contributo dos comentários para o debate sobre o tema, registam-se baixas percentagens em diversas subcategorias. Por outro lado, apuram-se elevadas percentagens, de $58 \%$ e $64 \%$, quando se trata de dar opinião, ou seja, adotar uma postura monológica, de baixo contributo para o debate.

Ferreira refere que para o modelo deliberativo importa indagar "em que medida os participantes dos grupos de discussão política virtuais fornecem ideias e informação à comunidade discursiva, ou apenas nela procuram informação, a partir de outros membros", e acrescenta que o que a pesquisa empírica revela é que, "sendo elevado o número de mensagens diariamente colocadas nos fóruns, tal quantidade não garante nem uma participação equitativa nem uma troca de opiniões substancial” (2010, p. 107).

Da análise aos resultados na categoria 'Contributo para o Debate', verifica-se que os comentários serviram "sobretudo para amplificar pontos de vista próprios, e raramente para reflectir o confronto com argumentos diversos", resultando "uma interacção frágil, fugaz, anónima, sem espessura política, e por isso pouco consistente com as exigências racionais de uma esfera pública forte (Ferreira, 2010, p. 111).

Fica, deste modo, limitada uma virtualidade da interatividade nos espaços de comentário a notícias, uma vez que os conhecimentos adicionais apresentados sobre as 
questões foram reduzidos. Frustrou-se assim o reforço do envolvimento cognitivo e o aumento da vontade de outros utilizadores contribuírem para a discussão (Ziegele et al., 2018, p. 1423).

As percentagens apuradas na subcategoria 'Fundamentação/racionalidade na ideia apresentada' evidenciam essa fraca interação discursiva, com valores de perto de $19 \%$ e de $12 \%$. A subcategoria "Acrescenta informação", igualmente importante para deliberação, revela também percentagens diminutas, de cerca de $4 \%$ e $7 \%$. No mesmo sentido, é nulo o contributo para o debate, com 5\% e $12 \%$.

Contudo, a capacidade deliberativa não se esgota em comentar, pode concretizar-se também lendo os comentários (Masip, Ruiz-Caballero, \& Suau, 2019).

\section{Quadro 5}

Civilidade

\begin{tabular}{cccc}
\hline Categoria & Subcategoria & $\begin{array}{c}\text { Ocorrências }-J N \\
\text { edição digital }\end{array}$ & $\begin{array}{c}\text { Ocorrências - } \\
\text { Observador }\end{array}$ \\
\hline Civilidade & Trolling & $44(21,46 \%)$ & $2(3,39 \%)$ \\
& Flaming & $12(5,85 \%)$ & $4(6,78 \%)$ \\
& Nenhum daqueles & $149(72,68 \%)$ & $53(89,83 \%)$ \\
\hline
\end{tabular}

Os comportamentos de flaming e o trolling são apontados em muitas pesquisas de comunicação política como fazendo parte da natureza da comunicação online. Trata-se de comportamentos de incivilidade que, muitas vezes, surgem associados a situações de anonimato dos seus autores. É frequente verificar-se o recurso a comportamentos mais agressivos quando as formulações agressivas já fazem parte da mensagem de outros comentadores (Gonçalves, 2018, p. 605), que poderão ainda resultar de comportamentos de afiliação, de imitação inconsciente.

Thorsten Quandt (2018, p. 41 s) designa a presença de trolls nos comentários de notícias, e em outros espaços dialógicos da Internet, como "participação sombria". Podem assumir-se como manipuladores individuais, "fomentadores de ódio com diferentes origens, motivações e comportamentos de participação", que tanto "podem atacar artigos ou tópicos específicos, como podem desviar o ódio orientado pelo conteúdo para os atores mencionados no artigo ou os próprios jornalistas". 
Os participantes sombrios têm ideias e mensagens extremas, e tentam levá-las ao público com zelo missionário e por todos os meios necessários. Assim, enquanto o conceito entusiasta de participação esperava uma motivação excecional do público normal, a participação sombria apenas assume exceções motivadas da norma. Como tal, um requisito para o conceito é facilmente cumprido, o futuro da participação sombria é, paradoxalmente, brilhante. (Quandt, 2018, p. 43)

Springer et al. (2015, p. 810) associam o trolling a motivações de entretenimento, que também são inerentes à interação social online. Dahlberg (2001), afirma que, além do engano identitário, o troll pode ter como objetivo embaraçar, perturbar, provocar, Às vezes chamado trolling, o engano identitário no ciberespaço tem como objetivo embaraçar, causar raiva e perturbar, e por vezes é impulsionado por objetivos mais sérios, em que se inclui a manipulação e desinformação de natureza política.

O engano na deliberação ocorre em situações em que um participante intencionalmente engana os outros a acreditar que as intenções, necessidades, desejos e interesses foram apresentados honestamente. Trata-se de um problema bastante generalizado nos grupos de discussão em linha. (Dahlberg, 2001)

Os comentários analisados revelaram que um número significativo deste tipo de comportamentos hostis e insultuosos, com destaque para o trolling no $J N$, estava associado a insinuações de envolvimento em atos de corrupção quando se tratava de mostrar alguma simpatia com o visado, ou perante alertas de moderação, em virtude de o visado ainda beneficiar da presunção de inocência. Noutros casos tratou-se de ofensas diretas à integridade moral e à autodeterminação sexual.

Após alguns ataques, e alguns contra-ataques discursivos, as vítimas acabaram por desaparecer do fórum. A liberdade, o respeito pelas diferenças, pela diversidade de opinião, inerentes à vivência democrática, são violados, e assim são preteridos requisitos normativos da deliberação, da tolerância e da sinceridade.

Ziegele et al. (2017, p. 321) fazem notar que estudos recentes apontam, como efeitos nocivos dos comentários incivilizados, um desgaste na cognição dos valores democráticos, que levam a atitudes polarizadas, e "têm um impacto negativo na qualidade noticiosa percebida dos meios de comunicação" social. 


\section{Quadro 6}

Posicionamento em relação ao assunto

\begin{tabular}{cccc}
\hline Categoria & Subcategoria & $\begin{array}{c}\text { Ocorrências - JN } \\
\text { edição digital }\end{array}$ & $\begin{array}{c}\text { Ocorrências - } \\
\text { Observador }\end{array}$ \\
\hline & Positivo em relação ao assunto & $16(7,80 \%)$ & $1(1,69 \%)$ \\
Posicionamento & $\begin{array}{c}\text { Negativo em relação ao assunto } \\
\text { Concordância em relação a outro } \\
\text { comentário }\end{array}$ & $103(50,24 \%)$ & $37(62,71 \%)$ \\
& $\begin{array}{c}\text { Discordância em relação a outro } \\
\text { comentário }\end{array}$ & $51(24,88 \%)$ & $11(18,64 \%)$ \\
& Nenhum daqueles & $11(5,37 \%)$ & $5(8,48 \%)$ \\
\hline
\end{tabular}

O posicionamento dos comentários foi dominantemente negativo em relação ao assunto, o que se pode explicar pelo facto de José Sócrates, e os seus alegados crimes de corrupção, serem objeto de elevada censura pública. Os autores dos comentários replicam aqui esse sentimento público. A divergência de opiniões foi também marcante, o que se pode entender com o facto de estar a ser comentado um tema controverso. No Observador, os posicionamentos estão mais radicalizados. Poderão resultar de alguma tendência grupal, o que empobrece as trocas comunicacionais.

\section{Quadro 7}

Partilha argumentativa e reflexão

\begin{tabular}{cccc}
\hline Categoria & Subcategoria & $\begin{array}{c}\text { Ocorrências - } \\
\text { JN edição digital }\end{array}$ & $\begin{array}{c}\text { Ocorrências - } \\
\text { Observador }\end{array}$ \\
\hline Reflexividade & $\begin{array}{c}\text { Incorpora contributos de } \\
\text { outros participantes }\end{array}$ & $75(36,59 \%)$ & $11(18,64 \%)$ \\
& $\begin{array}{c}\text { Não incorpora contributos } \\
\text { de outros }\end{array}$ & $130(63,41 \%)$ & $48(81,36 \%)$ \\
\hline
\end{tabular}


James Fishkin, como se referiu anteriormente, considera necessárias três condições para as práticas de deliberação, e uma delas é a oportunidade para a reflexão sobre novas mensagens e para o debate reflexivo.

Os participantes nos espaços de comentário dos dois jornais parecem utilizar de forma um pouco frágil o potencial que os arautos da ciberdemocracia atribuem à Internet, para a participação e troca de argumentos. A troca de argumentos e a reflexão são reduzidas, apenas $37 \%$ no $J N$ e $19 \%$ no Observador. Os participantes revelam uma baixa disponibilidade para refletir e para mudar de opinião se confrontados com um argumento mais válido.

A combinação destes dados com os de quadros anteriores sugere que os participantes pretendem mais emitir opinião do que partilhar opiniões e ideias ou estabelecer uma comunicação de acordo com os padrões de racionalidade do modelo deliberativo.

Quanto mais os indivíduos consideram os argumentos dos outros e os incorporam com os seus, mais tenderão a modificar gradualmente os seus comportamentos originais. O que estes resultados revelam é que poucos foram aqueles que atenderam aos argumentos rivais.

\section{Quadro 8}

Entendimento do assunto

\begin{tabular}{cccc}
\hline Categoria & Subcategoria & $\begin{array}{c}\text { Ocorrências }-J N \\
\text { edição digital }\end{array}$ & $\begin{array}{c}\text { Ocorrências - } \\
\text { Observador }\end{array}$ \\
\hline $\begin{array}{c}\text { Entendimento do } \\
\text { assunto em debate }\end{array}$ & Contributo explícito & $57(28,64 \%)$ & $14(23,73 \%)$ \\
& Nenhum daqueles & $57(28,64 \%)$ & $22(37,29 \%)$ \\
& & $85(42,71 \%)$ & $23,98 \%)$ \\
\hline
\end{tabular}

Dos participantes que deram um contributo para o debate, apenas uma pequena parte o fez de forma aberta. O contributo explícito é de $29 \%$ no $J N$ e de $24 \%$ no Observador. Em percentagens ainda mais elevadas, a participação nos comentários não teve como destino o debate, mas outros tipos de presença.

Não se registou uma acentuada atitude crítico-racional que o modelo deliberativo aponta, mas, em parte, visões individuais e contributos indiretos, ou até ausência de contributo às temáticas em discussão. 
Perante esta apatia, podem trazer-se aqui à discussão alguns tópicos sobre os constrangimentos apontados à participação em fóruns. $\mathrm{O}$ facto de uma boa parte dos participantes o fazer anonimamente, ou com perfis aparentemente falsos, parece não ter sido fomentador de um diálogo aberto, sem receios nem inibições. Ou estar-se-á perante o replicar dos constrangimentos que se verificam offline, de desigualdades discursivas, de inibições pelo estatuto cultural ou social, ou de fatores de protagonismo? E perante o desconforto que a exposição pública causaria tenderam a evitar contribuir para o debate, ou a fazê-lo de forma muito condicionada?

Apurar as causas destas atitudes exigiria um estudo mais aprofundado, que extravasa o âmbito deste artigo.

\section{CONSIDERAÇÕES FINAIS}

$\mathrm{Da}$ análise dos comentários às notícias publicadas nos $J N$ digital e no Observador somos levados a considerar que, enquanto prática discursiva, eles estão ainda bastante aquém da democracia deliberativa idealizada por Jürgen Habermas e outros autores seguidores do modelo.

No entanto, os espaços de comentário às notícias nos jornais têm em si um elevado potencial de diálogo, do público com os mediadores e dos públicos entre si, alimentando, assim, a ideia de uma esfera pública virtual. Mesmo que o ideal deliberativo tenha ficado frustrado, os participantes nos espaços de comentário dinamizaram, na sua maioria, uma conversação pública civilizada e seguindo padrões democráticos.

Os media online, ao mesmo tempo que informam, fornecem ferramentas para a atuação política, ao recorrerem ao potencial democrático desta plataforma que é a Internet.

No rol das vantagens políticas da internet, insiste-se com frequência nas novas possibilidades de expressão que permitem a um cidadão ou a um grupo da sociedade civil alcançar, sem maiores mediações institucionais, outros cidadãos (...). Nesse sentido, a internet pode desempenhar um papel importante na realização da democracia deliberativa, porque pode assegurar aos interessados em participar do jogo democrático dois dos seus requisitos fundamentais: informação política atualizada e oportunidade de interação. (Gomes, 2005, p. 220) 
No entanto, não se pode ignorar a existência de assimetrias que impõem constrangimentos ao ideal deliberativo. Estudos apontam que o uso da Internet está concentrado nos jovens e nos grupos com maior potencial económico. Igualmente, não se pode negligenciar que não basta dispor de um computador e de acesso à rede, pois a participação online exige ainda um conjunto de destrezas pessoais.

Ferreira (2012, p. 47) refere que o discurso em deliberações online "está marcado por todo um conjunto de elementos limitadores", que em muitos aspetos são semelhantes às formas tradicionais de discursividade, e que para identificar os constrangimentos à igualdade de oportunidades "é necessário distinguir analiticamente entre acesso e influência”.

Distingamos, assim, os dois aspectos do problema. Em primeiro lugar, a deliberação supõe igualdade no plano dos recursos necessários ao acesso por parte de cada indivíduo aos dados e argumentos em questão, sem qualquer restrição ou constrangimento. Depois, num segundo nível, a deliberação requer igual capacidade para apresentar, de forma persuasiva, os próprios argumentos ou reivindicações. (Ferreira, 2012, p. 47)

A realidade, segundo o mesmo autor (Ferreira, 2012, p. 26), levanta ainda outras questões, que são a de saber se, estabelecidas as condições básicas para a deliberação ocorrer, "os públicos fracos" conseguirão assumir-se como interlocutores plenos, ou se será necessário "um modelo de democracia deliberativa adequada a condições de injustiça".

Apesar de vários estudos demonstrarem que a Internet "aumenta a capacidade de comunicação de forma desigual”, e que as discussões políticas replicam desigualdades do offline (Ferreira, 2010, p. 108), ela dispõe de reconhecidas potencialidades para aumentar a participação democrática.

Embora os comentários analisados sobre as notícias do JN digital e do Observador sobre a desfiliação de José Sócrates evidenciem as principais questões levantadas em diversos estudos, seria essencial questionar um conjunto de tópicos que ao longo deste artigo foram enunciados. Importaria saber como se agregam essas pessoas, que lideranças sobressaem nesses fóruns, que lideranças se desenvolvem, se estão a replicar um ativismo político real, e que identidades procuram ocultar por detrás de perfis fictícios.

Uma grande parte dos participantes nos comentários que foi possível identificar por imagem fotográfica integra o grupo que se convencionou designar de "terceira 
idade", já liberto da vida ativa, e por isso tendencialmente com mais tempo livre. Foi possível verificar, por exemplo, que um dos participantes apresentou idêntico comentário nos dois jornais analisados. Um outro participante no espaço do JN é um conhecido e prolífero articulista de uma comunidade designada de "Diálogos Lusófonos".

Pela observação de comunicações cruzadas que se entabulavam no espaço de comentários, percebeu-se que alguns participantes já se conheciam, porventura de outros fóruns, e chegaram mesmo a unir-se no trolling a outros membros.

Apesar das fragilidades discursivas que ainda se expressam nesses fóruns, é relevante para a vivência democrática que os media tradicionais que se converteram ao digital aceitem o público como parte do processo de produção das notícias, como diz Gillmor. O tipo de interação que aí se desenvolve não será ainda o mais profícuo para o robustecimento da democracia e para abrir caminho ao ideário deliberativo. É, contudo, um exercício de participação política que tenderá a fazer o seu caminho.

A exemplo do que aponta Quandt (2018, p. 37), quer no $J N$, quer no Observador, não se verificou interatividade entre comentadores de notícias e jornalistas, negligenciando-se um canal que foi criado pelo próprio meio de comunicação onde trabalham. A moderação dos comentários também não foi realizada, e esta é encarada como fator favorável para criar um clima de desenvolvimento da deliberação Masip et al. (2019).

Schäfer (2015, p. 327) afirma que, apesar da proliferação de trabalhos académicos, não é possível estabelecer até que ponto existe uma esfera pública digital e quais os seus impactos na sociedade. Por sua vez, Papacharissi realça que através da investigação realizada se pode apontar que a "deliberação política pode, de facto, ter lugar online" (2002, p. 24).

A incorporação da Internet nos media convencionais vem, assim, reforçar a pertinência da teoria da democracia deliberativa, enquanto concepção de democracia que assenta num ideal de autonomia política baseada na racionalidade prática dos cidadãos, cuja deliberação pública tem como propósito influenciar o processo de tomada de decisão por parte do sistema político.(Silva M. T., 2013, p. 83)

A generalidade dos media portugueses pouco mais tem feito do que criar esses espaços de comentário, com intuitos comerciais, que deixam abandonados ao gáudio belicista de comentadores com tempo, de um ou outro bem-intencionado, e de 
alguns mal-intencionados. Abrindo o diálogo dos seus jornalistas com os leitores, talvez consigam estabelecer um outro pacto de confiança e conquistar outros públicos, reforçando a sua legitimação perante a sociedade.

\section{REFERENNCIAS}

Carrapatoso, M. S. (4 de maio de 2018). O "embaraço" de Sócrates com o PS. O texto do "animal feroz" nas entrelinhas. Observador.pt. Obtido em 25 de setembro de 2020, de https://observador.pt/2018/05/04/o-embaraco-de-socrates-com-o-psa-carta-do-animal-feroz-nas-entrelinhas/

Castells, M. (2003). O Poder da Identidade - A Era da Informação: Economia, Sociedade e Cultura (Vol. II). (A. Lemos, \& R. Espanha, Trads.) Lisboa: Fundação Calouste Gulbenkian.

Coe, K., Kenski, K., \& Rains, S. A. (2014). Online and Uncivil? Patterns and Determinants of Incivility in Newspaper Website Comments. Journal of Communication, 658-679. https://doi.org/10.1111/jcom.12104

Condesso, F. D. (2007). Direito da Comunicação Social. Coimbra: Almedina.

Dahlberg, L. (1 de Março de 1998). Cyberspace and the Public Sphere: Exploring the Democratic Potential of the Net . Convergence, 4(1), 70-84. https://doi. org/10.1177/135485659800400108

Dahlberg, L. (1 de outubro de 2001). Computer-Mediated Communication and the Public Sphere: a Critical Analysis. Journal ofComputer-Mediated Communication, 7(1). https://doi.org/10.1111/j.1083-6101.2001.tb00137.x

Dahlberg, L. (2004). Net Public Sphere Research: Beyond The First Phase. Javnost The Public, 11(1), 27-44. https://doi.org/10.1080/13183222.2004.11008845

Dahlberg, L. (2011). Re-constructing digital democracy: An outline of four 'positions'. new media \& society, 13(6), 855-872. https://doi.org/10.1177/1461444810389569

Dahlgren, P. (2018). Media, Knowledge and Trust: The Deepening Epistemic Crisis of Democracy. Javnost - The Public, 25(1-2), 20-27. https://doi.org/10.1080/131 83222.2018.1418819 
Ferreira, G. B. (Primavera/Verão de 2010). Internet e Deliberação a Discussão Política em Fóruns Online. Media \& Jornalismo, Vol. 9, N. ${ }^{\circ} 1$ (N.o 16), 99-114.

Ferreira, G. B. (2012). Novos media e vida cívica: Estudos sobre deliberação, internet e jornalismo. Covilhã: Livros LabCom, Ubi.

Fishkin, J. (5 de junho de 2013). Making Deliberative Democracy Real. YouTube. Obtido em 27 de setembro de 2020, de https://youtu.be/Hr1MqokjqRQ?t=213

Freelon, D. G. (2010). Analyzing online political discussion using three models of democratic communication. new media \& society, 12(7), 1172-1190. https://doi. org/10.1177/1461444809357927

Gillmor, D. (2005). Nós, os Media. Barcarena: Editorial Presença.

Gomes, W. (setembro/dezembro de 2005). A democracia digital e o problema da participação civil na decisão política. revista Fronteiras - estudos midiáticos, VII(3), 214-222.

Gonçalves, J. (2018). Aggression in news comments: how context and article topic shape user-generated content. Journal of Applied Communication Research, 46(5), 604-620. https://doi.org/10.1080/00909882.2018.1529419

Habermas, J. (1998). «Razonable» versus «verdadero», o la moral de las concepciones. Em J. Habermas, \& J. Rawls, Debate sobre el liberalismo político (pp. 145-181). Barcelona: Ediciones Paidós.

Masip, P., Ruiz-Caballero, C., \& Suau, J. (2019). Audiencias activas y discusión social en la esfera pública digital. Artículo de evisión. El profesional de la información, $28(2)$.

Papacharissi, Z. (2002). The virtual sphere: The internet as a public sphere. new media \& society, 4(1), 9-27. https://doi.org/10.1177/14614440222226244

Papacharissi, Z. (2004). Democracy online: civility, politeness, and the democratic potential of online political discussion groups. new media \& society, 6(2), 259283. https://doi.org/10.1177/1461444804041444

Quandt, T. (2018). Dark Participation. Media and Communication 6(4), 36-48. https://doi.org/10.17645/mac.v6i4.1519 
Rawls, J. (2014). A Lei dos Povos e a Ideia de Razão Pública Revisitada. (P. Barcelos, Trad.) Lisboa: Edições 70, Lda.

Rheingold, H. (1996). A Comunidade Virtual. Lisboa: Gradiva.

Schäfer, M. S. (2015). Digital Public Sphere. Em G. e. Mazzoleni, The International Encyclopedia of Political Communication (pp. 322-328). London: Wiley Blackwell. https://doi.org/10.1002/9781118541555.wbiepc087

Schudson, M. (2010). Formas de Cidadania Democrática e Funções do Jornalismo. Cidadania e Jornalismo / Citizenship and Journalism (pp. 23-42). Lisboa: Fundação Luso-Americana para o Desenvolvimento.

Silva, H. T. (4 de maio de 2018). Críticas levam Sócrates a abandonar o PS. JN.pt. Obtido em 25 de setembro de 2020, de https://www.jn.pt/nacional/interior/ criticas-levam-socrates-a-abandonar-o-ps-9306472.html

Silva, M. T. (2013). Participação e deliberação: um estudo de caso dos comentários às notícias sobre as eleições presidenciais brasileiras. Comunicação e Sociedade, 23, 82-95.

Springer, N., Engelmann, I., \& Pfaffinger, C. (2015). User comments: motives and inhibitors to write and read. Information, Communication \& Society, 18(7), 798815. https://doi.org/10.1080/1369118X.2014.997268

Young, I. M. (abril de 2014). Desafios ativistas à democracia deliberativa. Revista Brasileira de Ciência Política(13), 187-212. https://doi.org/10.1590/S010333522014000100008

Ziegele, M., Mathias, W., Quiring, O., \& Breiner, T. (2018). The dynamics of online news discussions: effects of news articles and reader comments on users' involvement, willingness to participate, and the civility of their contributions. Information, Communication \& Society, 21:10,, 21(10), 1419-1435. https://doi.or g/10.1080/1369118X.2017.1324505

Ziegele, M., Springer, N., Jost, P., \& Wright, S. (2017). Online user comments across news and other content formats: Multidisciplinary perspectives, new directions. Studies in Communication and Media, 6(4), 315-332. https://doi. org/10.5771/2192-4007-2017-4-315 